\title{
Zur Kenntnis der blauen Schwefelfarbstoffe
}

\section{Doctoral Thesis}

Author(s):

Bernasconi, Eduard

Publication date:

1932

Permanent link:

https://doi.org/10.3929/ethz-a-000095077

Rights / license:

In Copyright - Non-Commercial Use Permitted 
Diss. ETH: : $686 \mathrm{~B}$

\section{Zur Kenntnis der blauen Schwefelfarbstoffe}

Von der

Eidgenössischen Technischen Hochschule in Zürich zur Erlangung der

Würde eines Doktors der technischen Wissenschaften genehmigte

Promotionsarbeit

vorgelegt von

Eduard Bernasconi

Dipl. Ingenieur-Chemiker

aus Torricella (Tessin)

Nr. 686

Referent: Herr Prof. Dr. H. E. Fierz Korreferent: Herr Prof. Dr. L. Ruzicka

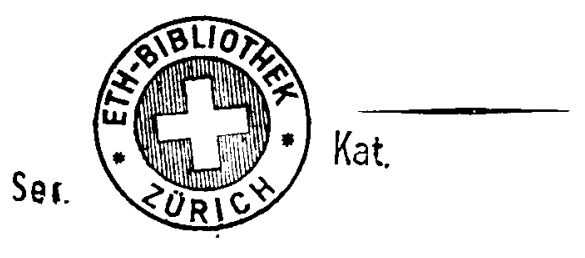

BASEL

Buchdruckerei Emil Birkhäuser \& Cie.

1932 
und $25 \mathrm{~cm}^{3}$ Alkohol $\left(\mathrm{Na}_{2} \mathrm{~S}_{3,3}\right)$. Dauer der Schmelze 28 Stunden, Ölbad $115^{\circ}$.

4,235 mg Subst. gaben $9,325 \mathrm{mg} \mathrm{CO}_{2}$ und $1,20 \mathrm{mg} \mathrm{H}_{2} \mathrm{O}$

$3,062 \mathrm{mg}$ Subst. gaben $0,200 \mathrm{~cm}^{3} \mathrm{~N}_{2}\left(21^{0}, 742 \mathrm{~mm}\right)$

$3,606 \mathrm{mg}$ Subst. gaben $5,480 \mathrm{mg} \mathrm{BaSO}$

Rückstand: $1 \%$.

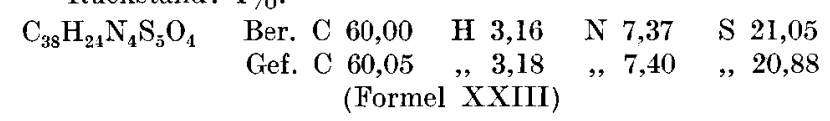

V. Zusammenfassung.

1. Durch eine geeignete Reinigung von Pyrogenindigo (Ciba), Immedialindon JBN (Comp. Nat. Mat. Col.) und Hydronblau R (I.G.) erhält man Körper von einheitlicher Zusammensetzung. Das Kerngebilde der Farbstoffe wird dabei nicht verändert.

2. Nach vollständiger Extraktion der Nebenprodukte haben diese Farbstoffe folgende Zusammensetzung:

a) Pyrogenindigo $\mathrm{C}_{36} \mathrm{H}_{20} \mathrm{~N}_{4} \mathrm{~S}_{5} \mathrm{O}_{3}$, bzw. $\mathrm{C}_{36} \mathrm{H}_{20} \mathrm{~N}_{4} \mathrm{~S}_{5} \mathrm{O}_{5}$ bei dem höher oxydierten Produkt.

b) Immedialindon $\mathrm{C}_{36} \mathrm{H}_{22} \mathrm{~N}_{4} \mathrm{~S}_{3} \mathrm{O}_{5}$.

c) Hydronblau $\mathrm{R}_{36} \mathrm{H}_{16} \mathrm{~N}_{4} \mathrm{~S}_{5} \mathrm{O}_{5}$.

3. Durch Titration mit Titantrichlorid lassen sich zwei Thiazinringe im Farbstoff nachweisen.

4. In der Küpe kondensieren sich zwei Mercaptangruppen des Farbstoffs mit Chloressigsäure. Das Kondensationsprodukt mit dem Pyrogenindigo hat die Zusammensetzung $\mathrm{C}_{40} \mathrm{H}_{26} \mathrm{~N}_{4} \mathrm{~S}_{5} \mathrm{O}_{6}$.

5. Bei genügend energischer Schwefelung des nach Richard Herz synthetisch aufgebauten, diesen Farbstoffen entsprechenden Trichlor-thiazins entsteht eine gleich hoch geschwefelte Verbindung von der Zusammensetzung $\mathrm{C}_{38} \mathrm{H}_{24} \mathrm{~N}_{4} \mathrm{~S}_{5} \mathrm{O}_{4}$. Je ein Chloratom des Thiazins wird dabei durch $\mathrm{OH}$ ersetzt; die Unlöslichkeit in wässrigen Alkalien erklärt sich durch den chemischen Charakter der Verbindung.

6. Durch Erhitzen des Schwefelfarbstoffes in Nitrobenzol erhält man blau bis rotviolett gefärbte Lösungen, die ein charakteristisches Spektrum zeigen. 